\title{
EFFECT OF AQUEOUS FERTILIZER ON SOIL MOISTURE CONTENT, DEPTH OF SEEDING AND SEEDLING EMERGENCE FOR WHEAT AVINASH KUMAR GAUTAM ${ }^{\mathbf{1}}$, ATUL KUMAR SHRIVASTAVA ${ }^{2} \&$ R. K. SAMAIYA ${ }^{\mathbf{3}}$ \\ ${ }^{1}$ Research Scholar, Department of Farm Machinery \& Power Engineering, CAE, JNKVV, Jabalpur, India \\ ${ }^{2}$ Professor and Head, Department of Farm Machinery \& Power Engineering, CAE, JNKVV, Jabalpur, India \\ ${ }^{3}$ Professor, Department of Plant breeding \& physiology, seed technology, JNKVV, Jabalpur, India
}

The soil moisture and the depth of seeding are the important factors, which determine the germination of seed in rain fed areas. A study was undertaken to determine the time of emergence of wheat seed. Pot experiment was conducted in the college of agricultural engineering, JNKVV, Jabalpur. The wheat seed GW-273 were used with four levels of moisture content, i.e. $100 \%, 85 \%, 65 \%$ and $50 \%$ of field capacity $(15.7 \%, 13.53 \%, 10.41 \%$ and $8.1 \%$ (DB)) and four levels of seeding depth were considered i.e. $2.5,5,7.5$ and $10 \mathrm{~cm}$. The laboratory results show that there was significant interaction observed with seed-depth, depth-moisture and moisture-seed. The time of emergence was prolonged for the $8.1 \%$ moisture content of 5-12 days. Hence, moisture availability and depth of seeding will influence the time of emergence.

KEYWORDS: Soil Moisture, Depth of Seed, Field Capacity, Time of Emergence \& Clay Loam
\end{abstract}

Received: Apr 17, 2017; Accepted: May 04, 2017; Published: May 25, 2017; Paper Id.: IJASRJUN201730

\section{INTRODUCTION}

India has an estimated 142 Mha cultivated area, of which about 57 Mha is irrigated and remainder 85 Mha is rain fed. Due to unavailability of sufficient soil moisture in the form of irrigation, main winter crop like wheat cannot be cultivated despite the suitability of the soil. Soil moisture stress assumes a major limiting factor determining the growth and yield of wheat in peninsular India. Moisture stress is one of the abiotic stresses, which affect the productivity. Emergence is probably the single most important event that affects the success of an annual crop. Rapid, uniform and complete emergence of vigorous seedlings, leads to high grain yield potential by shortening the time from sowing to complete ground cover, allows the establishment of an optimum canopy structure to minimize interplant competition, maximize crop yield. In rain fed areas, the depth of seedling and the available moisture, which influences the emergence of seedlings. The available moisture, water holding capacity and wilting point are mainly depends on type soil i.e. soil texture. For particular soil, it is necessary to calculate the requirement of soil moisture, which is necessary for proper germination of seed. Moisture requirement mainly depends on the root zone depth of the seed and type of seed. Moisture requirement for wheat in rain fed area is more than a gram. So, the aqua fertilizer applicator has its limiting conditions, it can't carry additional aqua fertilizer, it adds additional load on the tractor. So it is necessary to evaluate the interactions between depths of seeding, available moisture, which determines the capacity of aqua fertilizer. Hence, keeping in above view the pot experiment was conducted.

Hossein N, M, et al., (2009) conducted a pot experiment and compared the influence of different soil moisture content on seed emergence, and reported that the early emergence was observed in $10-50 \%$ field capacity 
as compared to $25 \%$ of field capacity. Maliwal et al., (2000) conducted a pot experiment at different moisture content of cotton seed to determine the seed emergence and reported highest and lowest germination was at 23.8 and $12 \%$ moisture content, respectively. Philip et al., (2009) conducted experiments on for seed to determine the germination and reported that the growth and biomass were higher at greater soil moisture variability and seed germination. Molatudi. Et al., (2009) studied the effect of seed size and planting depth on maize seedling emergence and growth and reported that the planting depth showed significant differences on the emergence of seedlings. Saeed et al., (2007) studied the effect of planting depth on seedling emergence and reported that emergence was decreased as depth of planting was increased. Stephen A. Et al., (2010) conducted experiments to determine the effects of planting depth, sediment grain size, and nutrients on 2 different seeds and reported that seedling emergence was inversely proportional to seedling emergence.

\section{MATERIAL AND METHODS}

\section{Determination of Available Soil Moisture}

Available soil moisture is a basic requirement of seed germination. In dry land areas, moisture availability at time of sowing is a major problem. To begin with, determination of available moisture at sowing depth was done and based on that estimation of aqueous fertilizer requirement in a given area was determined. The available soil moisture is the moisture that plants can use and it depends on soil texture also. The available soil moisture was calculated by using the formulae

ASM, $(\%)=\mathrm{FC},(\%)-\mathrm{WP},(\%)$

Where,

ASW = Available soil moisture, $\%$

FC = Field capacity, the upper limit of available moisture in which drainage ceases (Occurs at soil moisture tensions of 1/10 bar (10 container) for sandy soil and 1/3 bar (33 container) for other soils.

$\mathrm{WP}=$ Wilting point or lower limit of the soil moisture at which plant wilt permanently (Permanent wilting point occurs at 15 bars of soil moisture tension)

This will be helpful in determining the moisture requirement if soil type and soil texture pattern is known for dry land areas. With the help of above data total water and available water for different texture soils were also determined. Water holding capacity, in terms of available water in percent, for different soil texture designation was determined with the help of field capacity and wilting point levels of various texture soils.

\section{Determination of Aqueous Fertilizer Requirement}

The requirement of aqueous fertilizer in a given soil moisture environment depends on soil texture, field capacity, wilting point and available moisture in a particular soil. The first step in this direction was to estimate the requirement of additional soil moisture, which is just sufficient to meet the moisture abundantly, because moisture applicator has its own limitations w.r.t. Water carrying capacity and mode of aqueous fertilizer application. Also, any excess volume of water would be a hindrance in proper sowing of seed alongside of aqueous fertilizer. The estimation of aqueous fertilizer was done using the following formula.

$\mathrm{V}_{1}=(\mathrm{FC}-\mathrm{WP}) \times \rho \times \mathrm{d} \times \mathrm{w} \times \mathrm{n} \times \mathrm{W}$

Where, 


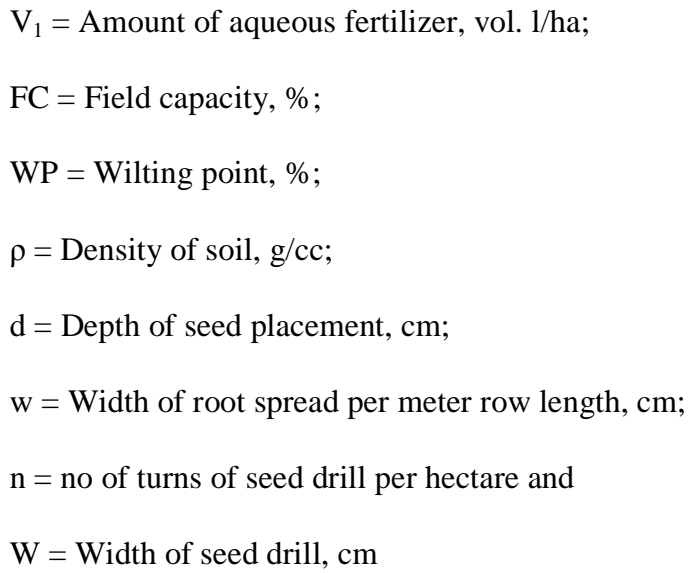

\section{Time of Seedling Emergence}

Pot experiment was conducted to determine the seedling emergence at the laboratory of college of agricultural engineering, Jabalpur. The wheat crop variety GW 273 was undertaken for the study. Polyvinyl chloride (PVC) pots of diameter; $13 \mathrm{~cm}$ and height; $10 \mathrm{~cm}$ were used for seedling emergence test. Soil collected from the field was dry and filled with pot. Measured volume of water was added to each pot, which helped to compute the moisture content on a volumetric basis. The graded wheat seed was used for the experiment. Ten seeds were placed at 2.5, 5, 7.5 and $10 \mathrm{~cm}$ depth in part in the first week of December 2016. Four levels of soil moisture (100, 85, 65 and 50\% of field capacity on dry weight basis) were considered for the study. The complete randomized design, factorial was undertaken with three replications. The soil moisture was tried to be constant throughout the experimentation by adding water to pot at each two day intervals. The water requirement was calculated on the weight loss basis. The number of days were recorded as the seedling grows up to $3 \mathrm{~mm}$ height, and considered as time of emergence.

\section{RESULTS}

\section{Aqueous Fertilizer Requirement for Clay Loam Soil}

The aqueous fertilizer requirement for wheat in clay loam soil condition was found to be in the range of 5500-6500 1/ha, considering 9\% soil moisture as wilting point. It is the utmost importance for determining the size of the aqua fertilizer drill.

\section{Time of Emergence of Wheat at different Soil Moisture Levels}

The soil moisture 100, 85, 65 and $50 \%$ of field capacity on volumetric basis was found equivalent to $15.7 \%$, $13.53 \%, 10.41 \%$ and $8.1 \%$ on a dry basis, respectively in clay loam soil. In given depth of $5 \mathrm{~cm}$ of soil, with increased soil moisture content from 8.1 to 15.7 , the time of emergence decreased from 9 to 4 days. For moisture variation, of 10.41 to 15.7, the time of emergence decreased from 6 to 4 days. Similarly for moisture variation of 15.7 and $8.1 \%$, the time of emergence ranged as 4-7 and 9-12 for the depth 5 and $10 \mathrm{~cm}$, respectively. There was significant interaction observed between depth-moisture, depth-seed and moisture-seed. The time of emergence of wheat seeds is given in the table below. 
Table 1: Time of Emergence at different Soil Moisture and Varying Seeding Depth

\begin{tabular}{|c|c|c|c|c|c|}
\hline \multirow{2}{*}{ S. No. } & \multicolumn{5}{|c|}{ Time of Emergence, Days } \\
\cline { 2 - 6 } & \multirow{2}{*}{ Moisture Content (db) } & \multicolumn{2}{|c|}{ Seeding Depth (Aqueous Fertilizer) } \\
\cline { 3 - 6 } & & $\mathbf{2 . 5}$ & $\mathbf{5 . 0}$ & $\mathbf{7 . 5}$ & $\mathbf{1 0}$ \\
\hline 1. & 15.7 & 3 & 4 & 6 & 9 \\
\hline 2. & 13.53 & 4 & 5 & 8 & 10 \\
\hline 3. & 10.41 & 5 & 7 & 9 & 11 \\
\hline 4. & 8.1 & & & & \\
\hline
\end{tabular}

Table 2

\begin{tabular}{|c|c|c|c|c|c|}
\hline \multirow{3}{*}{ S. No. } & \multicolumn{5}{|c|}{ Time of Emergence, Days } \\
\cline { 2 - 6 } & \multirow{3}{*}{ Moisture Content (db) } & \multicolumn{3}{|c|}{ Seeding Depth (Controlled) } \\
\cline { 2 - 6 } & & $\mathbf{2 . 5}$ & $\mathbf{5 . 0}$ & $\mathbf{7 . 5}$ & $\mathbf{1 0}$ \\
\hline 1. & 15.7 & 4 & 7 & 9 & 10 \\
\hline 2. & 13.53 & 4 & 7 & 10 & 11 \\
\hline 3. & 10.41 & 5 & 8 & 11 & 11 \\
\hline 4. & 8.1 & 6 & 9 & 12 & 12 \\
\hline
\end{tabular}

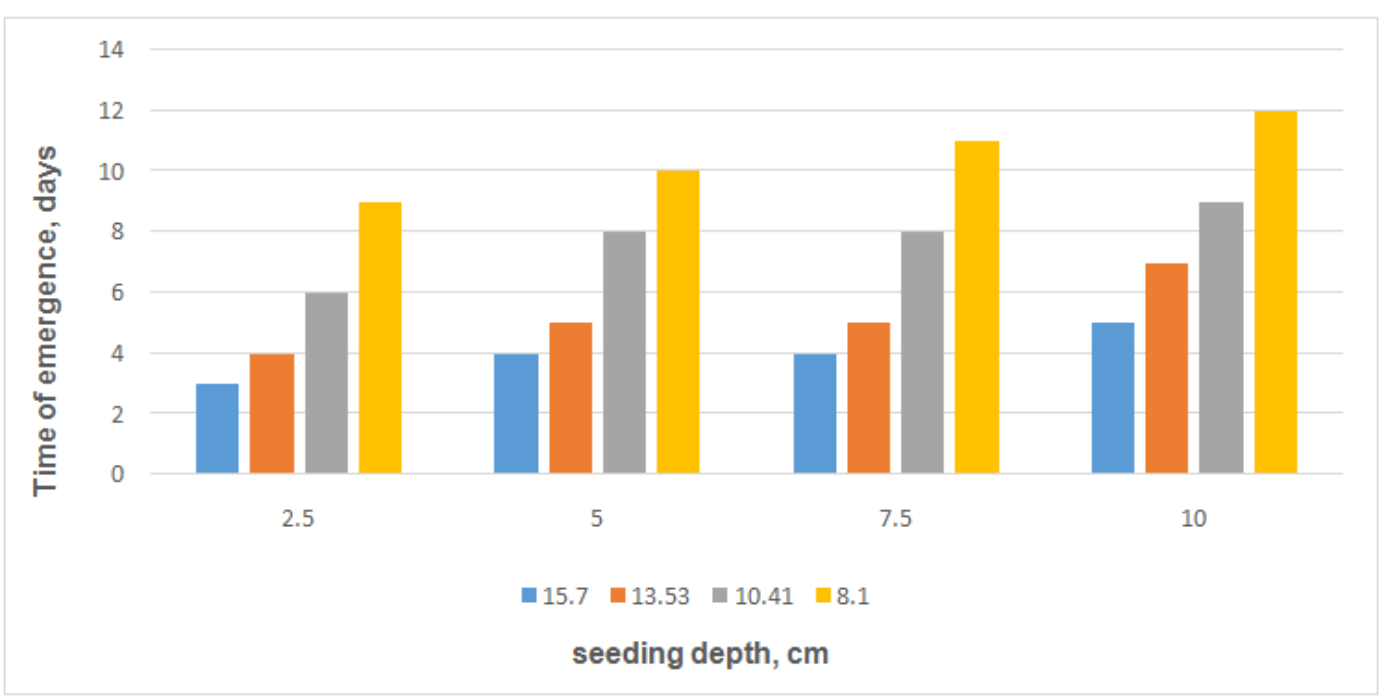

Figure 3.1: Time of Emergence for Aqueous Fertilizer

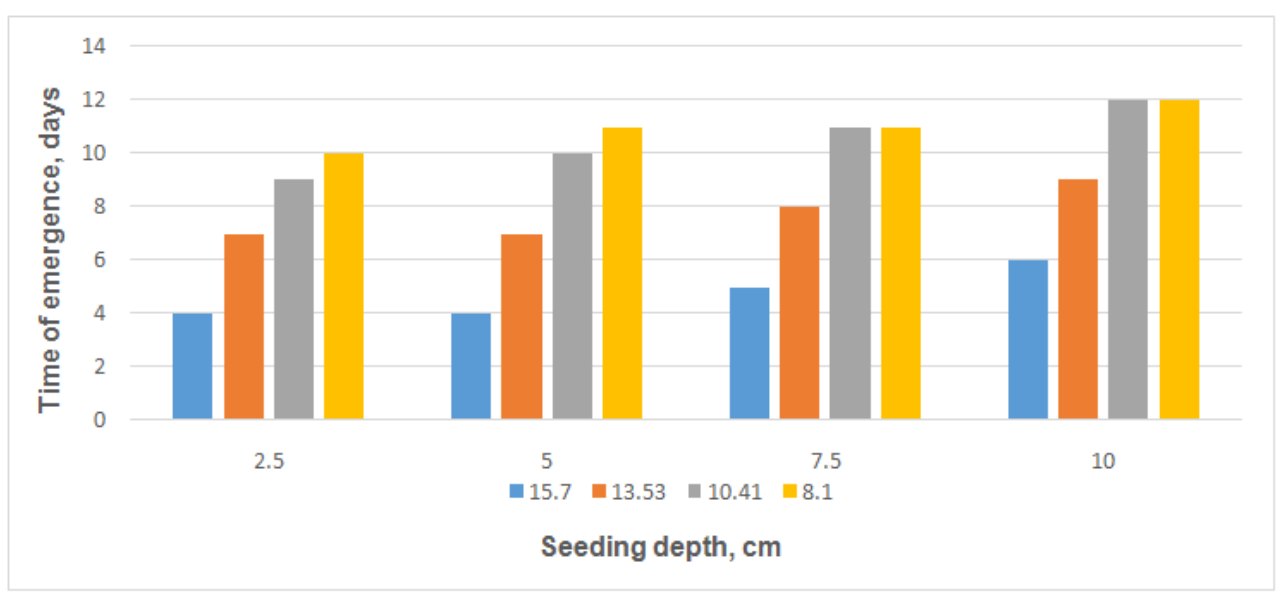

Figure 3.2: Time of Emergence (Controlled) 


\section{DISCUSSIONS}

The requirement of aqua fertilizer for the clay loam soil is $5500-6500 \mathrm{l} / \mathrm{ha}$ estimated. The aqua fertilizer requirement for chickpea was calculated about 7500-8500 1/ha (Raghvendra et al.) hence, the requirement of aqua fertilizer lower than chickpea. So, this parameter decides the capacity of the aqua fertilizer tank, this reduces the extra load on the tractor. Time of emergence was excessively long i.e. 9-12 days for the depth of sowing $10 \mathrm{~cm}$. Hence, the optimum depth of sowing was $5 \mathrm{~cm}$ because of this depth the water is easily available to the plants and also, it reduces the draft.

\section{CONCLUSIONS}

The depth of seeding and available moisture is influenced by time of emergence. The time of emergence was prolonged, as the soil moisture and seeding depth varies. There was significant interaction observed between controlled and aqua fertilizer doses, and also significant interaction was observed between seed-depth, moisture-seed and depth moisture.

\section{REFERENCES}

1. Majnoun Hosseini, N., Siddique, K.H.M., Palta, J.A. and Berger, J. 2009. Effect of soil misture content on seedling emergence early growth of some chickpea (cicer arietinum L.) genotypes. J. Agric. Sci. Technol. 11:401-411.

2. Maliwal, G.L. 2000. Effect of soil moisture and water logging on seed germination and seedling growth of cotton under Bhal condition. Indian J. PI. Physiol. 5(2):174-176.

3. Phillip, A.F., Megan, J.S. 2009. Germination, survival, and growth of grass and forb seedlings: Effects of soil moisture variability. Acta Oecologica. 35:679-684.

4. Raghvendra V., 2011. Development of aqua ferti seed drill for chickpea (Cicer arietinumL). M.Sc. thesis, IARI, New Delhi.

5. Saeed A.M, Uzma Younis, Altaf, A.D., Akram, M. and Shehzadi, S. 2007. Effect of planting depths on emergence and seedling morphology of Praecitriulus fistulosus (stocks) Pangalo and Pennisetum typhoides (burm.f) Stapf. Pak. J. Pl. Sci., 13(1):5-11.

6. Stephen Ailstock, M., Deborah, J.S. and Dale Magoun, A. 2010. Effects of planting depth, sediment grain size and nutrients on Ruppia maritime and Potamogeton perfoliatus seedling emergence and growth. Restoration Ecology. 18(4) : 574-583. 
